\title{
Quadrupled Hamstring Graft Diameter Adequacy in Anterior Cruciate Ligament Reconstruction Using Patient Anthropometry: A Prospective Cohort Study in Indian Males
}

Sunil Kumar ${ }^{1}$, Harish Kumar ${ }^{1}$, Prashant P. Singh ${ }^{1}$, Pranav Sharma ${ }^{1}$, Amit K. Rai Sharma ${ }^{1}$, Mohit K. Singh ${ }^{1}$, Rajendra Kumar ${ }^{1}$

1. Orthopaedics, Uttar Pradesh University of Medical Sciences, Etawah, IND

Corresponding author: Sunil Kumar, sksrimsnr@gmail.com

\section{Abstract}

\section{Background and aim}

The diameter of the graft used for the reconstruction of the anterior cruciate ligament (ACL) is an important determinant for the overall strength and future outcome of the operative procedure. Preoperative prediction of quadrupled hamstrings autograft (QHAG) diameter can prove to be of help in forecasting the need for augmentation or alternative grafts like quadriceps, bone-patellar tendon-bone autograft, and synthetic grafts. The relationship between the preoperatively assessed anthropometric parameters and the obtained quadrupled hamstrings graft diameter has not been extensively studied, especially in the population of Indian origin. This study aimed at investigating whether a correlation exists between the measured anthropometric parameters like age, weight, height, thigh circumference, and body mass index (BMI) and the intraoperatively obtained diameter of hamstring graft for ACL reconstruction in the study population of Indian male subjects.

\section{Study design}

A prospective cohort study conducted in a tertiary care center and teaching hospital in a district in central Uttar Pradesh, India.

\section{Methods}

The preoperative anthropometric data (age, height, weight, BMI, and thigh circumference of the injured side) of 73 Indian male subjects undergoing primary ACL reconstructive surgeries between May 2018 and August 2020 were prospectively collected, and their respective intraoperative QHAG diameters measured and recorded. Pearson's correlation test was employed to determine the correlation between the preoperative demographic and anthropometric data and the obtained corresponding graft diameters. Simple linear regression was performed to obtain the graphical plots and determine the relationship between the dependent and independent variables. Of these, the variables showing significant association were subjected to stepwise linear regression to identify and exclude the confounder(s) and obtain the predicted equation.

Review began 06/02/2021 Review ended 06/15/2021 Published 06/25/2021

\section{(c) Copyright 2021}

Kumar et al. This is an open access article distributed under the terms of the Creative Commons Attribution License CC-BY 4.0., which permits unrestricted use, distribution, and reproduction in any medium, provided the original author and source are credited.

\section{Results}

The study comprised 73 male participants. The study participants' mean age was found to be 33.7 years, mean height was $173.1 \mathrm{~cm}$, mean weight was $71.2 \mathrm{~kg}$, mean BMI was $23.7 \mathrm{~kg} / \mathrm{m}^{2}$, mean thigh circumference was $50.4 \mathrm{~cm}$, and the obtained mean graft diameter was $8.0 \mathrm{~mm}$. A strongly positive correlation was observed between height and the graft diameter $(\mathrm{r}=0.940, \mathrm{P}=0.000)$ and thigh circumference and the graft diameter $(\mathrm{r}=0.769, \mathrm{P}=0.000)$. In contrast, weight showed a moderately positive correlation with the graft diameter $(\mathrm{r}=0.514, \mathrm{P}=0.000)$. A very weakly positive correlation was observed between the BMI of the subjects and the obtained graft diameters $(\mathrm{r}=0.236, \mathrm{P}=0.045)$. However, no correlation was observed between the age and the final graft diameters $(\mathrm{r}=0.140, \mathrm{P}=0.238)$. Subsequent linear regression analysis indicates that only height ( $\mathrm{R}^{2}=0.883, \mathrm{P}=0.000$; strong) and the thigh circumference $\left(\mathrm{R}^{2}=0.591, \mathrm{P}=0.000\right.$; moderate) share a significant predictive value for the obtained QHAG. Both height and thigh circumference together were good predictors for graft diameter as determined by multiple regression $(F(2,70)=272.372, P<0.001)$, with an $\mathrm{R}^{2}$ of 0.886 .

\section{Conclusion}

Certain anthropometric parameters depict a positive correlation with the QHAG diameter and can assist in preoperative planning, predicting the possible harvested graft diameter and the need for alternative grafts or augmentation during ACL reconstructive surgeries. 
Categories: Orthopedics, Trauma

Keywords: acl, anterior cruciate ligament, anthropometry, quadrupled hamstring graft diameter, height, autograft

\section{Introduction}

Injury to the anterior cruciate ligament (ACL) is one of the most common athletic injuries encountered globally [1]. It is among the most common injuries around the knee [2]. The overall incidence of ACL injuries has been reported to be considerably higher in males than females [3]. Owing to its high incidence, ACL is the most frequently reconstructed ligament of the knee [4]. Among the variety of graft choices available for ACL reconstruction like hamstring tendon (HT) autograft, bone-patellar tendon-bone graft (BPTB), and allograft, HT autografts (semitendinosus and gracilis) have emerged to become the graft of choice (45-89\% of the study population) for most orthopedic and knee surgeons, followed by BPTB graft (2-41\%) and allograft (2-17\%) [5]. Most surgeons prefer single-bundle reconstruction as the technique of choice for ACL reconstruction [5]. This progressive inclination toward HT autograft is well justified by the associated donorsite morbidity, higher risk of anterior knee pain, and loss of knee extension with BPTB autografts as compared with HT autografts, as has also been included in the Cochrane recommendations, even though both HT and BPTB autografts have comparable tensile properties, stiffness, functional outcomes, and knee stability [6-11].

The graft used most often, i.e., the HT autograft, utilizes the semitendinosus and gracilis tendons, derived from the affected side, doubled up twice onto themselves to create a four-strand graft (the quadrupled hamstring autograft). It has been reported that the tensile strength of the graft used increases significantly with an increase in the graft diameter [12].

Several studies have recommended the use of grafts with diameters equal to or greater than $8 \mathrm{~mm}$, and that reconstruction with grafts lesser than $8 \mathrm{~mm}$ diameter has a higher risk of graft failures, poorer functional outcomes, and higher revision rates [13-16]. Owing to the high inter-individual variability in the size of HTs, the diameter of the derived graft varies and is often unpredictable. Preoperative prediction of the adequacy of the HT graft harvested during the surgery can prove to be of assistance in operative planning and help guide the surgeon regarding the need for augmentation or alternative grafts or fixation techniques, and subsequently counsel the patient regarding the possible graft choices and the functional outcome. It is, therefore, imperative to devise methods to predict the potential size of quadrupled hamstring autograft to be harvested intraoperatively. Several studies have attempted to address this by testing the relationship between various anthropometric parameters and the graft diameter, but no consensus has been achieved [16-24]. Moreover, only a few studies have been undertaken to study this relationship in the Asian population, let alone in India.

This prospective study aimed to determine whether any correlation exists between the various demographic and anthropometric parameters like age, weight, height, body mass index (BMI), and thigh circumference, and the harvested quadrupled hamstring autograft intraoperatively in ACL reconstruction among male subjects of Indian origin. We hypothesized that no such correlation exists between the dependent and the independent variables to analyze whether the harvested graft size can be preoperatively predicted using anthropometric measurements in our study population.

\section{Materials And Methods}

The study was conducted in a tertiary care center and teaching hospital in a district in central Uttar Pradesh, India. Approval of the study was acquired from the Institutional Ethics Committee, Uttar Pradesh University of Medical Sciences (Reference Number 125/2018). We used a prospective cohort study design to study the correlation of demographic and anthropometric data of subjects with the quadrupled hamstring autograft diameter in the ACL reconstruction. The enrollment of study subjects was done between May 2018 and August 2020 with appropriate written and informed consent.

\section{Study participants \\ Population Under Study}

All patients who present with a symptomatic acute ACL injury or a chronic ACL deficiency (categorized on the basis of time elapsed from injury till presentation) [25].

\section{Inclusion Criteria}

Male patients aged 17 years or more, presenting with an acute ACL injury who remained symptomatic after adequate rehabilitation (for three to six months, tailored according to patient's vocational needs and demands), and patients with chronic ACL deficiency planned for primary ACL reconstruction using anatomical single-bundle quadruple HT autograft. 


\section{Exclusion Criteria}

Females; revision ACL reconstruction surgeries; patients undergoing ACL reconstruction using grafts other than HTs; double-bundle hamstring graft reconstructions; ACL injuries associated with other significant complete ligamentous injuries; ACL injuries with associated meniscal injuries that required suturing; acute ACL injury with tibial spine avulsion.

\section{Study design}

We adopted a purposive sampling strategy to obtain the sample size. From a sampling frame of 108 eligible patients who presented during the study duration and after exclusion of the subjects who did not fulfill the inclusion criteria, a total of 73 patients consented to the procedure and were enrolled to participate in the study (N=73) (Figure 1).

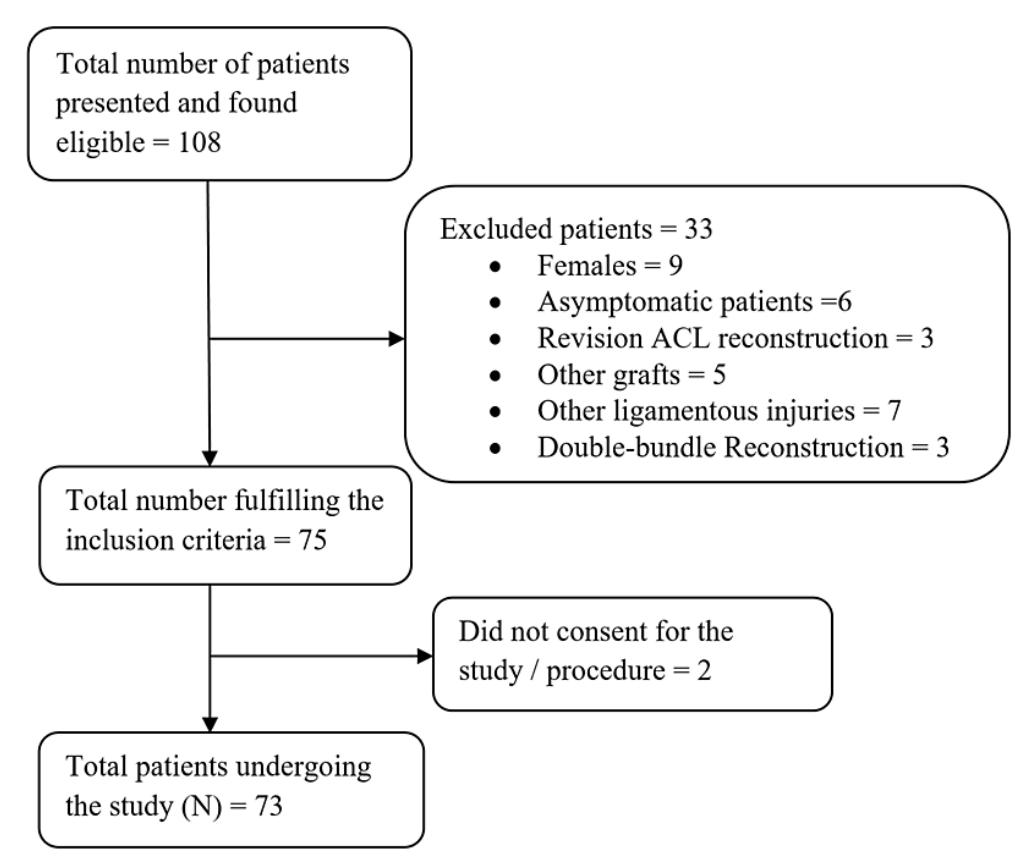

\section{FIGURE 1: Procedure adopted for enrolling study participants}

$\mathrm{N}$ : total number of study participants; ACL: anterior cruciate ligament.

The study procedure and its significance were explained in detail to the study participants. Written and informed consent was obtained. The demographic profile, such as age and the anthropometric data, including weight, height, BMI, and thigh circumference, were obtained prospectively from the study participants before undergoing arthroscopic ACL reconstruction using quadrupled hamstring autograft. Blinding was achieved by ensuring that the surgeon, who himself is not involved in the operative procedure, collected the data for all the study subjects. Weight (in $\mathrm{kg}$ ) and height (in $\mathrm{cm}$ ) were recorded using the same weighing scale and stadiometer, respectively, for all the patients. The thigh circumference (in $\mathrm{cm}$ ) of the affected side was measured using the same nonstretchable tape at a point $15 \mathrm{~cm}$ proximal to the superior pole of the patella, with the patient in supine position and the hip and the knee in full extension. The surgery was performed by the same certified orthopedic surgeon, trained and experienced in arthroscopic knee procedures, and both the semitendinosus and the gracilis hamstring grafts harvested using the same technique in all the patients. A standard 4-cm-long incision anteromedially over the proximal tibia was used to expose the pes anserinus for harvesting the hamstrings graft after releasing the tendons with an open-end tendon stripper. After separating muscle fibers from the tendons and trimming the tendons, a whipstitch was placed at both ends of each tendon with a nonabsorbable polyester suture. Then a four-strand graft was made by looping the derived tendons onto themselves. The final graft diameter measurement was then obtained by passing the graft through sizing cylinders (in increments of $0.5 \mathrm{~mm}$ ) of the ACL reconstruction measurement guide (Arthrex). The diameter of the smallest calibrated sizing cylinder through which the entire graft could pass through smoothly was considered the final graft diameter. The operating surgeon, who was blinded from the anthropometric data, recorded the graft diameter intraoperatively. Singlebundle anatomic ACL reconstruction procedure was then carried out using standard techniques. Tightrope and interference screws were used as the femoral and tibial end fixation techniques, respectively, and these were kept similar in all the subjects. The relationship between the preoperatively measured anthropometric 


\section{Cureus}

variables with the graft diameter obtained during surgery was then analyzed.

\section{Statistical analysis}

We calculated the descriptive statistics of the various variables to describe the demographic profile of the population under study. The normality of the data distribution was ascertained using tests of normality. Pearson's correlation test was used to determine whether there exists any correlation between anthropometric measurements (independent variables) and the obtained size of the quadrupled hamstrings autograft (dependent variable). The bivariate analysis further identified variables associated with graft diameter at a significance level of $\mathrm{P}<0.05$. From this, the variables found to be associated at a P-value of $<0.05$ were further included in a stepwise linear regression to arrive at the predicted equation. Additionally, the potential confounder(s) were identified and excluded from the equation. A P-value of less than 0.05 $(<5 \%)$ was considered statistically significant at a 95\% confidence interval. All the outcome analyses were performed using the SPSS version 24.0 (IBM, Armonk, NY, USA).

\section{Results}

A total of 73 male patients participated in the study. The means of the predictor and outcome variables, the anthropometric data, and the demographic profile of the study population are depicted in Table 1.

\begin{tabular}{|c|c|c|}
\hline Variable & Mean \pm SD & Range \\
\hline Age (years) & $33.7 \pm 11.2$ & $17-57$ \\
\hline Duration since injured (weeks) & $15.1 \pm 7.2$ & $4-32$ \\
\hline Height (cm) & $173.1 \pm 5.3$ & 160.0-183.4 \\
\hline Weight (kg) & $71.2 \pm 13.1$ & $42.1-93.4$ \\
\hline BMI $\left(\mathrm{kg} / \mathrm{m}^{2}\right)$ & $23.7 \pm 3.9$ & 15.5-33.1 \\
\hline Thigh circumference (cm) & $50.4 \pm 6.8$ & $39.1-64.7$ \\
\hline Graft diameter (mm) & $8.0 \pm 0.8$ & $6.5-9.5$ \\
\hline
\end{tabular}

\section{TABLE 1: Characteristics of the study participants $(\mathrm{N}=73)$}

$\mathrm{N}$ : total number of study participants; SD: standard deviation; BMI: body mass index.

The analysis of preoperatively recorded data showed that the mean age of the patients at presentation was $33.7 \pm 11.2$ years, the mean duration since injury was $15.1 \pm 7.2$ weeks, the mean height of the study subjects was $173.1 \pm 5.3 \mathrm{~cm}$, the mean weight was $71.2 \pm 13.1 \mathrm{~kg}$, the mean BMI was $23.7 \pm 3.9 \mathrm{~kg} / \mathrm{m}^{2}$, and the mean thigh circumference was $50.4 \pm 6.8 \mathrm{~cm}$. Out of the 73 patients, $30(41.09 \%)$ had sustained an injury to their left knee, whereas 43 (58.9\%) had their right knee injured. Road traffic accidents $(n=33,45.2 \%)$ were the most common mode of injury, followed by sports and athletics-related events ( $n=27,37 \%$ ) (Table 2). 


\section{Cureus}

\begin{tabular}{|c|c|c|c|}
\hline \multicolumn{2}{|l|}{ Variables } & Frequency (n) & Percentage \\
\hline \multirow{6}{*}{ Mode of Injury } & Fall from stairs & 4 & 5.5 \\
\hline & Fall on ground & 5 & 6.8 \\
\hline & Road traffic accident & 33 & 45.2 \\
\hline & Sports injury & 27 & 37.0 \\
\hline & Twisting injury & 4 & 5.5 \\
\hline & Total (N) & 73 & 100.0 \\
\hline \multirow{3}{*}{ Side of limb involved } & Left & 30 & 41.09 \\
\hline & Right & 43 & 58.9 \\
\hline & Total $(\mathrm{N})$ & 73 & 100.0 \\
\hline
\end{tabular}

TABLE 2: Distribution of the mode of injury and the injured side among study participants

$\mathrm{N}$ : total number of study participants.

The mean intraoperative diameter of the final quadrupled hamstrings graft was found to be $8.0 \pm 0.8 \mathrm{~mm}$. Out of the total participants, 45 (61.6\%) had a graft diameter of $8 \mathrm{~mm}$ or more, the most frequent size being 8 $\mathrm{mm}(23.3 \%, \mathrm{n}=17)$ (Table 3).

\begin{tabular}{|c|c|c|c|}
\hline Graft diameter (cm) & Frequency & Percentage & Cumulative percentage \\
\hline 6.5 & 6 & 8.2 & 8.2 \\
\hline 7.0 & 10 & 13.7 & 21.9 \\
\hline 7.5 & 12 & 16.4 & 38.4 \\
\hline 8.0 & 17 & 23.3 & 61.6 \\
\hline 8.5 & 13 & 17.8 & 79.5 \\
\hline 9.0 & 10 & 13.7 & 93.2 \\
\hline 9.5 & 5 & 6.8 & 100.0 \\
\hline Total & 73 & 100.0 & 100.0 \\
\hline
\end{tabular}

TABLE 3: Frequency distribution of graft sizes $(\mathrm{N}=73)$

$\mathrm{N}$ : total number of study participants.

Computation and analysis of the Pearson's correlation coefficient revealed a strongly positive correlation of the patients' height $(r=0.940, \mathrm{P}=0.000)$ and thigh circumference $(\mathrm{r}=0.769, \mathrm{P}=0.000)$ with the graft diameter, a moderately positive correlation between patients' weight $(\mathrm{r}=0.514, \mathrm{P}=0.000)$ and the graft diameter, and a very faintly positive correlation between patients' $\mathrm{BMI}(\mathrm{r}=0.236, \mathrm{P}=0.045)$ and the graft diameter. No significant correlation was obtained between the patients' age $(\mathrm{r}=0.140, \mathrm{P}=0.238)$ and the quadrupled hamstring graft diameter harvested (Table 4). 


\section{Cureus}

\begin{tabular}{|c|c|c|}
\hline Variables & r-Value & P-value \\
\hline Age & 0.140 & 0.238 \\
\hline Height & 0.940 & 0.000 \\
\hline Weight & 0.514 & 0.000 \\
\hline BMI & 0.236 & 0.045 \\
\hline Thigh circumference & 0.769 & 0.000 \\
\hline
\end{tabular}

TABLE 4: Distribution and correlation of anthropometric profiles with graft diameter (Pearson's correlation test applied)

SD: standard deviation; BMI: body mass index.

A simple linear regression analysis was carried out, and the coefficient of determination was calculated for each independent demographic and anthropometric variable, keeping the obtained graft diameter as the dependent variable. It was determined that only height $\left(\mathrm{R}^{2}=0.883, \mathrm{P}=0.000\right)$, thigh circumference $\left(\mathrm{R}^{2}=0.591\right.$, $\mathrm{P}=0.000)$, and weight $\left(\mathrm{R}^{2}=0.264, \mathrm{P}=0.000\right)$ are significant predictors of the final graft diameter, the strongest association being with the patients' height. On the contrary, no significant relationship was observed between the age of the patients $\left(\mathrm{R}^{2}=0.020, \mathrm{P}=0.238\right)$ with the intraoperatively obtained graft diameter, whereas BMI $\left(\mathrm{R}^{2}=0.056, \mathrm{P}=0.045\right)$ showed only a weak association with the graft diameter (Table 5) (Figures 2-6). Multiple regression analysis was performed to determine the best linear combination of independent variables for predicting the final graft diameter. Weight and BMI were found to be the potential confounders on stepwise multiple regression models. Subsequently, the graft diameter was predicted based on the height and the thigh circumference. A significant regression equation was found, $(F(2,70)=272.372, P<0.001)$, with an $\mathrm{R}^{2}$ of 0.886 . Participants' predicted graft diameter is equal to $-16.574+0.011$ (thigh circumference) +0.139 (height), where both height and thigh circumference were measured in centimeters. Participants' graft diameter increased by $0.011 \mathrm{~mm}$ with each centimeter increase in thigh circumference and by $0.139 \mathrm{~mm}$ with each centimeter increase in height of the subjects, respectively. Both height and thigh circumference were significant predictors of graft diameter.

\begin{tabular}{|c|c|c|}
\hline Variables & $\mathbf{R}^{2}$ & P-value \\
\hline Age & 0.020 & 0.238 \\
\hline Height & 0.883 & 0.000 \\
\hline Weight & 0.264 & 0.000 \\
\hline BMI & 0.056 & 0.045 \\
\hline Thigh circumference & 0.591 & 0.000 \\
\hline
\end{tabular}

TABLE 5: Results of the simple linear regression analysis between the graft diameter and the anthropometric profiles

$\mathrm{R}^{2}$ : coefficient of determination; BMI: body mass index. 


\section{Cureus}

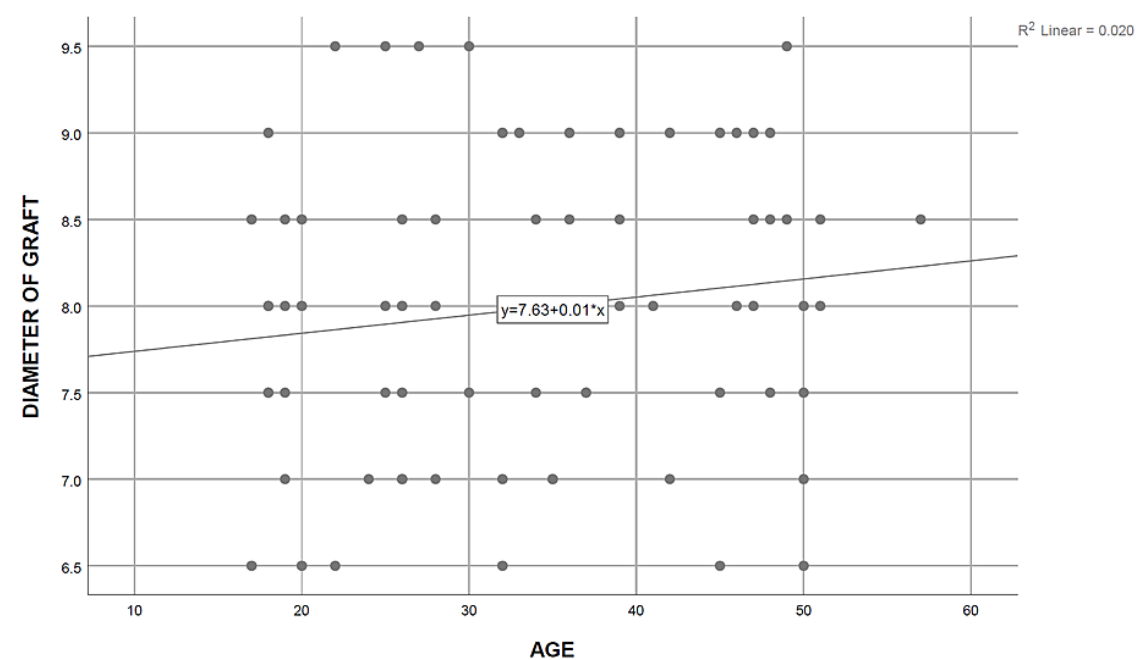

FIGURE 2: Curve estimate of the simple linear regression between the graft diameter and age

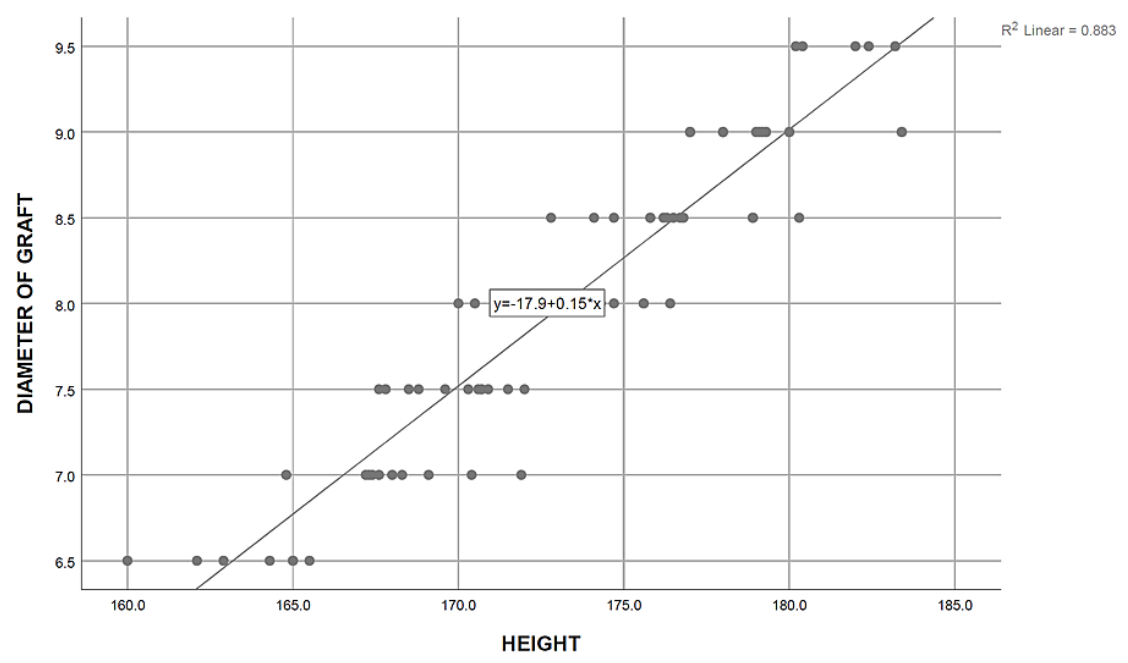

FIGURE 3: Curve estimate of the simple linear regression between the graft diameter and height 


\section{Cureus}

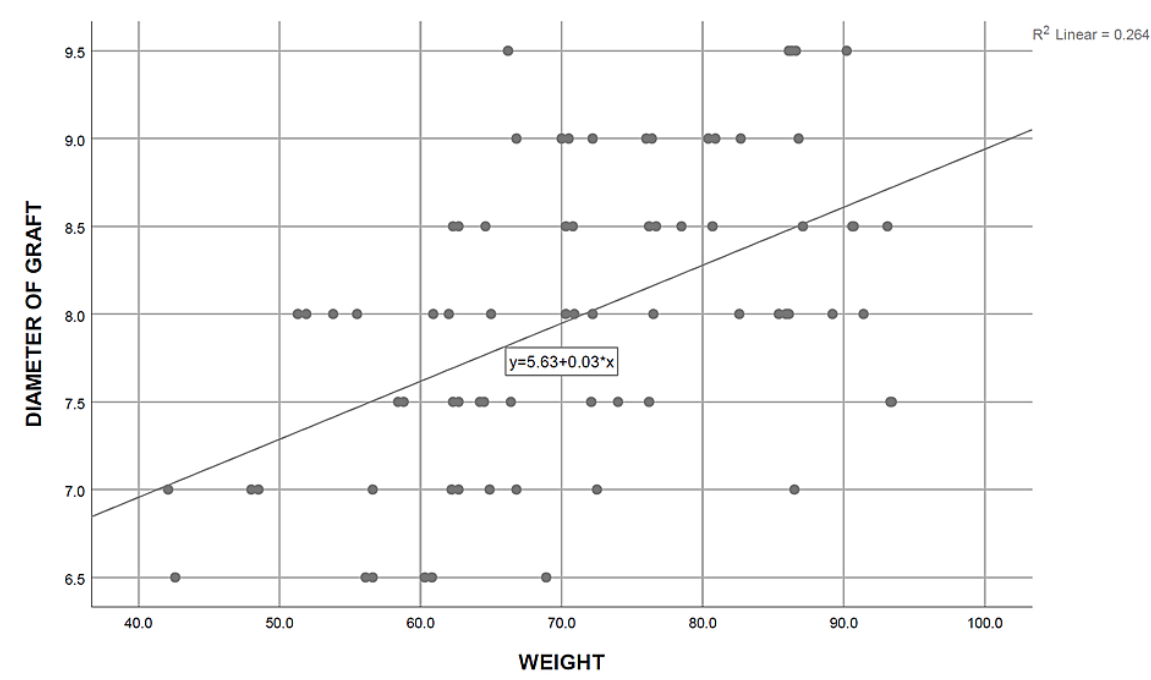

FIGURE 4: Curve estimate of the simple linear regression between the graft diameter and weight

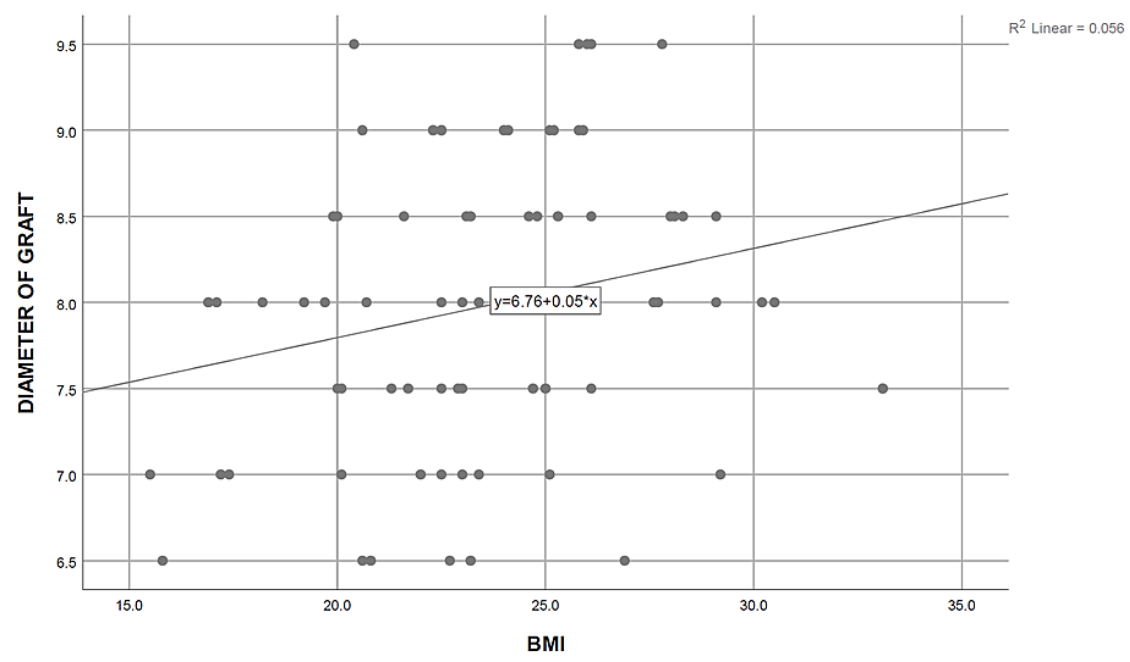

FIGURE 5: Curve estimate of the simple linear regression between the graft diameter and BMI

BMI: body mass index 


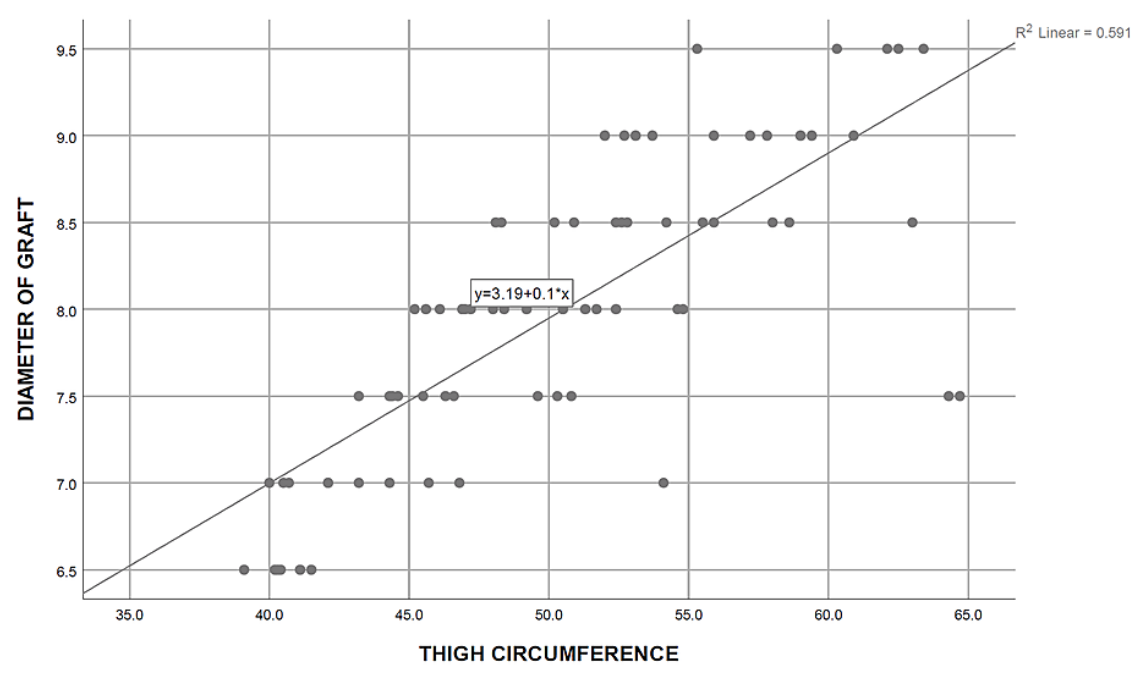

FIGURE 6: Curve estimate of the simple linear regression between the graft diameter and thigh circumference

\section{Discussion}

Quadrupled hamstring autograft is the most preferred graft option for ACL reconstruction [5]. The diameter of graft harvested and utilized for reconstruction has a significant relationship with the strength of the graft [12]. The knowledge of the intraoperative diameter of the graft to be harvested can help predict the acceptability of the graft and its future implications like the risk of failure and need for revision surgery and, hence, can guide the surgeon with operative planning.

Upon analysis of the study outcomes based on our study population of 73 Indian males undergoing primary ACL reconstruction, we observed a positive correlation between the height, thigh circumference, weight, and the BMI of the study subjects, with the diameter of harvested HT autograft. Of these variables, height and thigh circumference were found to have a strong correlation, weight was only moderately correlated, and BMI had a poor correlation with the obtained graft diameter. Patients' age showed no correlation with the graft diameter. Further analysis using linear regression showed that only height $\left(\mathrm{R}^{2}=0.883, \mathrm{P}=0.000\right)$, thigh circumference $\left(\mathrm{R}^{2}=0.591, \mathrm{P}=0.000\right)$, and weight $\left(\mathrm{R}^{2}=0.264, \mathrm{P}=0.000\right)$ were significantly associated with the size of the graft diameter, with the height being the most strongly related. This strength of the relationship was justified to be strong, as up to $88.3 \%$ of the variance in the harvested graft diameter could be attributed to height, and thigh circumference could explain up to $59.1 \%$ of the variability in the graft diameter. In contrast, only $26.4 \%$ and $5.6 \%$ of the graft diameter variance could be attributed to weight and BMI, respectively. Age had no statistically significant relationship with the harvested graft diameter.

Furthermore, on analyzing multiple regression models, the relationship with weight and BMI was also disregarded due to their confounding effect on the outcome. Height was shown to have the most significant predictive value for the harvested graft diameter. It was observed that thigh circumference alone had only a moderately significant relationship with the dependent variable (graft diameter); however, together with height, they showed a positive association with the dependent variable and a significant predictive value for harvested graft diameter, with an $\mathrm{R}^{2}$ of 0.886 . This indicates that $88.6 \%$ of the variance in the graft diameter could be explained by the model having the combination of these two variables. The combination of both height and thigh circumference together significantly predicted the final graft diameter.

Among all the independent variables, height was determined to be the most significant predictor of harvested quadrupled hamstring graft diameter in ACL reconstruction. This stands in corroboration with multiple studies conducted previously [18,19,21,26,27]. In a study conducted by Tuman et al., it was determined that height is the best predictor for HT graft diameter in subjects of both genders, although the correlation was the strongest in females [18]. They observed that the graft diameter was related to height, mass, age, and gender but had no relation with the BMI of the subjects. Based on this, Treme et al. further analyzed these outcomes in a separate study and concluded that graft diameter is most strongly correlated with weight and thigh circumference of the subjects, whereas there is no correlation of graft diameter with the age of the subjects [20]. Ma et al. reported height to be a specific predictor of graft diameter solely in males [19].

A significant correlation between the thigh circumference and the graft diameter of the subjects was 
observed in the preliminary analysis in our study, but upon further investigation using linear and multiple regressions, only a moderate predictive power for the graft diameter could be ascertained to the measured thigh circumference alone. This is in contrast to the findings of Treme et al. and Asif et al., who documented thigh circumference to be a significant predictor of the HT graft diameter [17,20]. Gupta et al. also showed a weak correlation between the thigh circumference and the graft diameter [28].

We observed a weak correlation between the weight of the subjects and the size of grafts; however, upon multiple regression analysis, it was found to act as a confounder. Weight has also been reported to have no significant association with the graft diameter in other studies previously [19,21]. Whereas, in contrast, several authors have reported the graft diameter being strongly related to the weight of the subjects $[18,20,26,27]$. These differences in observations can possibly be attributed to the varying degrees of body fat in different individuals, which contributes to the weight but not the muscle mass of the individuals.

It has previously been shown that the graft diameter is not related to BMI, as demonstrated in multiple separate studies [18,21, 23,24,26,27]. Our analysis exhibits a similar finding regarding BMI. One possible cause for this particular finding could be that BMI takes into account the whole body mass and not just the lean muscle mass. Similarly, our study found no statistically significant correlation between age and graft diameter, as has also been demonstrated before [18-21,24,26]. Although a study by Moghamis et al., in contrast, reported a moderately significant positive correlation between age and the harvested graft diameter, there was no correlation with height or BMI [23].

Studies involving both genders have demonstrated that females have a significantly smaller graft diameter than men $[18,26]$. Treme et al., in their research, exhibited that ipsilateral thigh circumference remains the sole important predictor for graft diameter in females and that use of gender-specific recommendations provides better accuracy in predictions and identification of individuals at risk of insufficient graft diameter [20]. In another similar study, Stergios et al. could not derive any statistically significant predictor for graft diameter in female patients [29]. Based on this premise, female subjects requiring ACL reconstruction had been excluded from our study, and only male subjects were enrolled.

Our findings strongly correlate with the similar studies undertaken previously on subjects of Indian origin, especially in regard to height having the strongest correlation and being the most significant predictor $[17,22,24,28]$. Asif et al. concluded that the height and the thigh circumference of the subjects are significantly related to the hamstring graft diameter, whereas BMI has no influence on the same [17]. Challa et al. also reported height to be of most predictive influence on graft diameter for both males and females of their Indian study population but found no other variable to correlate with the graft diameter [24]. Similar outcomes were observed by Goyal et al., where they found only height to be most strongly related to the harvested graft diameter, although the strength of association between the two variables was only moderate [22]. Another study that supports the above findings is by Gupta et al., where height was found to be strongly correlated with the graft diameter, weight was moderately correlated, whereas thigh circumference was only weakly correlated with the intraoperatively observed graft diameter [28]. In addition to the above findings, a key conclusion in our study was the demonstration of superior predictive value for graft diameter when using a combination of height and thigh circumference.

\section{Limitations}

This study does not take into account the possible differences in measuring the thigh circumference due to the position of the patient (supine or standing) and the site of measurement $(15 \mathrm{~cm}$ from the superior pole of patella or mid-point between the mid-inguinal crease and the superior border of patella) and its possible effects on relationship with the final predicted graft diameter. Moreover, we measured the weight (and the $\mathrm{BMI}$ ) of the study subjects, which do not address the varying body fat percentages in different individuals and can be a potential source of discrepancy. Future studies with measurements of lean body mass instead can be of help in this regard. Also, studies with larger sample sizes are needed to ascertain the definitive relationship between the variables under study.

\section{Conclusions}

Preoperative measurements of certain anthropometric parameters can prove to be a valuable tool for predicting the adequacy of intraoperatively harvested graft diameter, the need for augmentation or alternative grafts, and the risk of failure or the graft used. This can further help reduce the operation time, postoperative pain, and scar if an alternative graft is chosen due to inadequacy.

Height remains the most consistent parameter among the variables studied for the prediction of the harvested quadrupled hamstrings autograft diameter, even in the study population of Indian males. The predictive value was seen to improve further when thigh circumference and height are used in combination.

\section{Additional Information}

Disclosures 
Human subjects: Consent was obtained or waived by all participants in this study. Institutional Ethics Committee - Uttar Pradesh University of Medical Sciences issued approval 125/2018. Informed consent was obtained from all participants in the study. Institutional Ethics Committee - Uttar Pradesh University of Medical Sciences issued approval 125/2018. . Animal subjects: All authors have confirmed that this study did not involve animal subjects or tissue. Conflicts of interest: In compliance with the ICMJE uniform disclosure form, all authors declare the following: Payment/services info: All authors have declared that no financial support was received from any organization for the submitted work. Financial relationships: All authors have declared that they have no financial relationships at present or within the previous three years with any organizations that might have an interest in the submitted work. Other relationships: All authors have declared that there are no other relationships or activities that could appear to have influenced the submitted work.

\section{References}

1. Kaeding CC, Léger-St-Jean B, Magnussen RA: Epidemiology and diagnosis of anterior cruciate ligament injuries. Clin Sports Med. 2017, 36:1-8. 10.1016/j.csm.2016.08.001

2. Singh N: International epidemiology of anterior cruciate ligament injuries . Orthop Res Online J. 2018, 3:10.31031/OPROJ.2018.03.000562

3. Sanders TL, Maradit Kremers H, Bryan AJ, et al.: Incidence of anterior cruciate ligament tears and reconstruction: a 21-year population-based study. Am J Sports Med. 2016, 44:1502-7. $10.1177 / 0363546516629944$

4. Bach Jr BR, Boonos CL: Anterior cruciate ligament reconstruction. AORN J. 2001, 74:151-64. 10.1016/S00012092(06)61524-X

5. Grassi A, Carulli C, Innocenti M, Mosca M, Zaffagnini S, Bait C; SIGASCOT Arthroscopy Committee: New trends in anterior cruciate ligament reconstruction: a systematic review of national surveys of the last 5 years. Joints. 2018, 6:177-87. 10.1055/s-0038-1672157

6. Mohtadi NG, Chan DS, Dainty KN, Whelan DB: Patellar tendon versus hamstring tendon autograft for anterior cruciate ligament rupture in adults. Cochrane Database Syst Rev. 2011, 2011:CD005960. 10.1002/14651858.CD005960.pub2

7. Pinczewski LA, Lyman J, Salmon LJ, Russell VJ, Roe J, Linklater J: A 10-year comparison of anterior cruciate ligament reconstructions with hamstring tendon and patellar tendon autograft: a controlled, prospective trial. Am J Sports Med. 2007, 35:564-74. 10.1177/0363546506296042

8. Maletis GB, Cameron SL, Tengan JJ, Burchette RJ: A prospective randomized study of anterior cruciate ligament reconstruction: a comparison of patellar tendon and quadruple-strand semitendinosus/gracilis tendons fixed with bioabsorbable interference screws. Am J Sports Med. 2007, 35:384-94. $10.1177 / 0363546506294361$

9. Hamner DL, Brown CH Jr, Steiner ME, Hecker AT, Hayes WC: Hamstring tendon grafts for reconstruction of the anterior cruciate ligament: biomechanical evaluation of the use of multiple strands and tensioning techniques. J Bone Joint Surg Am. 1999, 81:549-57. 10.2106/00004623-199904000-00013

10. Kautzner J, Kos P, Hanus M, Trc T, Havlas V: A comparison of ACL reconstruction using patellar tendon versus hamstring autograft in female patients: a prospective randomised study. Int Orthop. 2015, 39:125-30. 10.1007/s00264-014-2495-7

11. Miller SL, Gladstone JN: Graft selection in anterior cruciate ligament reconstruction . Orthop Clin North Am. 2002, 33:675-83. 10.1016/S0030-5898(02)00027-5

12. Boniello MR, Schwingler PM, Bonner JM, Robinson SP, Cotter A, Bonner KF: Impact of hamstring graft diameter on tendon strength: a biomechanical study. Arthroscopy. 2015, 31:1084-90. 10.1016/j.arthro.2014.12.023

13. Conte EJ, Hyatt AE, Gatt CJ Jr, Dhawan A: Hamstring autograft size can be predicted and is a potential risk factor for anterior cruciate ligament reconstruction failure. Arthroscopy. 2014, 30:882-90. 10.1016/j.arthro.2014.03.028

14. Magnussen RA, Lawrence JT, West RL, Toth AP, Taylor DC, Garrett WE: Graft size and patient age are predictors of early revision after anterior cruciate ligament reconstruction with hamstring autograft. Arthroscopy. 2012, 28:526-31.10.1016/j.arthro.2011.11.024

15. Mariscalco MW, Flanigan DC, Mitchell J, et al.: The influence of hamstring autograft size on patientreported outcomes and risk of revision after anterior cruciate ligament reconstruction: a Multicenter Orthopaedic Outcomes Network (MOON) Cohort Study. Arthroscopy. 2013, 29:1948-53. 10.1016/j.arthro.2013.08.025

16. Park SY, Oh H, Park S, Lee JH, Lee SH, Yoon KH: Factors predicting hamstring tendon autograft diameters and resulting failure rates after anterior cruciate ligament reconstruction. Knee Surg Sports Traumatol Arthrosc. 2013, 21:1111-8. 10.1007/s00167-012-2085-4

17. Asif N, Ranjan R, Ahmed S, Sabir AB, Jilani LZ, Qureshi OA: Prediction of quadruple hamstring graft diameter for anterior cruciate ligament reconstruction by anthropometric measurements. Indian J Orthop. 2016, 50:49-54. 10.4103/0019-5413.173521

18. Tuman JM, Diduch DR, Rubino LJ, Baumfeld JA, Nguyen HS, Hart JM: Predictors for hamstring graft diameter in anterior cruciate ligament reconstruction. Am J Sports Med. 2007, 35:1945-9. 10.1177/0363546507304667

19. Ma CB, Keifa E, Dunn W, Fu FH, Harner CD: Can pre-operative measures predict quadruple hamstring graft diameter?. Knee. 2010, 17:81-3. 10.1016/i.knee.2009.06.005

20. Treme G, Diduch DR, Billante MJ, Miller MD, Hart JM: Hamstring graft size prediction: a prospective clinical evaluation. Am J Sports Med. 2008, 36:2204-9. 10.1177/0363546508319901

21. Pereira RN, Karam FC, Schwanke RL, Millman R, Foletto ZM, Schwanke CH: Correlation between anthropometric data and length and thickness of the tendons of the semitendinosus and gracilis muscles used for grafts in reconstruction of the anterior cruciate ligament. Rev Bras Ortop. 2016, 51:175-80. 


\section{Cureus}

10.1016/j.rboe.2016.01.01

22. Goyal S, Matias N, Pandey V, Acharya K: Are pre-operative anthropometric parameters helpful in predicting length and thickness of quadrupled hamstring graft for ACL reconstruction in adults? A prospective study and literature review. Int Orthop. 2016, 40:173-81. 10.1007/s00264-015-2818-3

23. Moghamis I, Abuodeh Y, Darwiche A, Ibrahim T, Al Ateeq Al Dosari M, Ahmed G: Anthropometric correlation with hamstring graft size in anterior cruciate ligament reconstruction among males. Int Orthop. 2020, 44:577-84. 10.1007/s00264-019-04452-5

24. Challa S, Satyaprasad J: Hamstring graft size and anthropometry in south Indian population . J Clin Orthop Trauma. 2013, 4:135-8. 10.1016/j.jcot.2013.09.005

25. Flint JH, Wade AM, Giuliani J, Rue JP: Defining the terms acute and chronic in orthopaedic sports injuries: a systematic review. Am J Sports Med. 2014, 42:235-41. 10.1177/0363546513490656

26. Pinheiro LF Jr, de Andrade MA, Teixeira LE, et al.: Intra-operative four-stranded hamstring tendon graft diameter evaluation. Knee Surg Sports Traumatol Arthrosc. 2011, 19:811-5. 10.1007/s00167-010-1387-7

27. Thomas S, Bhattacharya R, Saltikov JB, Kramer DJ: Influence of anthropometric features on graft diameter in ACL reconstruction. Arch Orthop Trauma Surg. 2013, 133:215-8. 10.1007/s00402-012-1648-7

28. Gupta R, Malhotra A, Masih GD, Khanna T: Equation-based precise prediction of length of hamstring tendons and quadrupled graft diameter by various anthropometric variables for knee ligament reconstruction in Indian population. J Orthop Surg (Hong Kong). 2017, 25:2309499017690997. $10.1177 / 2309499017690997$

29. Stergios PG, Georgios KA, Konstantinos N, Efthymia P, Nikolaos K, Alexandros PG: Adequacy of semitendinosus tendon alone for anterior cruciate ligament reconstruction graft and prediction of hamstring graft size by evaluating simple anthropometric parameters. Anat Res Int. 2012, 2012:424158. $10.1155 / 2012 / 424158$ 